\title{
Air pollution modelling for birth cohorts: a time-space regression model
}

\author{
Elena Proietti ${ }^{1,4}$, Edgar Delgado-Eckert ${ }^{1}$, Danielle Vienneau ${ }^{2,3^{*}}$, Georgette Stern ${ }^{1,4}$, Ming-Yi Tsai ${ }^{2,3}$, Philipp Latzin ${ }^{1,4}$, \\ Urs Frey ${ }^{1}$ and Martin Röösli, ${ }^{2,3}$
}

\begin{abstract}
Background: To investigate air pollution effects during pregnancy or in the first weeks of life, models are needed that capture both the spatial and temporal variability of air pollution exposures.

Methods: We developed a time-space exposure model for ambient $\mathrm{NO}_{2}$ concentrations in Bern, Switzerland. We used $\mathrm{NO}_{2}$ data from passive monitoring conducted between 1998 and 2009: 101 rural sites (24,499 biweekly measurements) and 45 urban sites (4350 monthly measurements). We evaluated spatial predictors (land use; roads; traffic; population; annual $\mathrm{NO}_{2}$ from a dispersion model) and temporal predictors (meteorological conditions; $\mathrm{NO}_{2}$ from continuous monitoring station). Separate rural and urban models were developed by multivariable regression techniques. We performed ten-fold internal cross-validation, and an external validation using $57 \mathrm{NO}_{2}$ passive measurements obtained at study participant's homes.

Results: Traffic related explanatory variables and fixed site $\mathrm{NO}_{2}$ measurements were the most relevant predictors in both models. The coefficient of determination $\left(R^{2}\right)$ for the log transformed models were 0.63 (rural) and 0.54 (urban); cross-validation $R^{2} s$ were unchanged indicating robust coefficient estimates. External validation showed $R^{2} s$ of 0.54 (rural) and 0.67 (urban).

Conclusions: This approach is suitable for air pollution exposure prediction in epidemiologic research with time-vulnerable health effects such as those occurring during pregnancy or in the first weeks of life.

Keywords: Air pollution, $\mathrm{NO}_{2}$, Exposure, Pregnancy, Birth cohort

Abbreviations: AFU, Amt für Umweltschutz Stadt Bern, i.e. monitoring network in city of Bern; AQM, Air quality monitoring; BECO, Berner Wirtschaft, i.e. monitoring network in rural Bern; BILD, Basel-Bern Infant Lung Development; CORINE, Coordination of information on the environment, i.e. land cover data; ECMWF, European Centre for Medium-Range Weather Forecasts; ESCAPE, European Study of Cohorts for Air Pollution Effects; GIS, Geographic information system; IQR, Interquartile range; LUR, Land use regression; NABEL, National Observational Network for Airborne Pollutants; NO2, Nitrogen dioxide; R2, Coefficient of determination; RMSE, Root mean square error; VIF, Variance inflation factor.
\end{abstract}

\section{Background}

Air pollution exposure during early life, including pregnancy, may have consequences for the whole life and future generation as already demonstrated for smoking [1, 2]. Pregnancy is a vulnerable phase of life in which the fetus' organs and systems develop in a specific order,

\footnotetext{
* Correspondence: danielle.vienneau@unibas.ch

${ }^{2}$ Swiss Tropical and Public Health Institute (Swiss TPH), Socinstrasse 57, 4051, Basel, Switzerland

${ }^{3}$ University of Basel, Basel, Switzerland

Full list of author information is available at the end of the article
}

time and speed. Depending on the period of pregnancy, air pollutants may reach and harm the fetus in different ways [3]. The time scale of these windows of vulnerability may be in the order of months or trimesters [4]. For instance, there is evidence for the effect of air pollution exposure during the last trimester of pregnancy on infant lung function [5-7], for infant mortality for respiratory reason due to exposure to air pollution during the first trimester [8], and for different lymphocyte distribution depending on the air pollution exposure for 
different trimesters $[9,10]$. In the current literature, however, there is no consensus about the effect of air pollution on other birth outcomes such as birth weight or prematurity [11-15].

The assessment of exposure is a crucial step in the study of the potential adverse effects associated with air pollution. Errors in exposure measurements reduce the statistical power of a study [16] and bias the risk estimates to unity, both increasing the likelihood that real associations are not detected.

In birth cohort studies, models designed to accurately estimate individual traffic-related air pollution exposure for different biologically relevant time windows (i.e., during and after pregnancy) are therefore of extreme importance. A few birth cohorts have used dispersion models to estimate hourly or daily air pollution levels, and subsequently calculated exposure during pregnancy $[13,17,18]$. These models are very demanding in terms of data requirements and processing time, especially when the temporal and spatial resolution has to capture variation by season and within a few hundred meters. The easiest and most cost-effective way to estimate air pollution with the finest temporal resolution is to use data from fixed air quality monitoring (AQM) stations [19] with the disadvantage of having coarse spatial coverage. Inverse distance weighting and kriging may be used to model the spatial variability, though, depending on density of the monitors, complexity of topography, urbanization and meteorological conditions, these methods are often not sufficient to capture contrasts in exposures [19]. On the other hand, land use regression (LUR) models have been increasingly used to estimate long term exposure in cohort studies [20, 21]. In general LUR models focus on spatial variability over longer averaging periods, disregarding fine scale temporal variability, although attempts have been made to apply post-hoc temporal adjustments to LUR estimates by means of fixed air quality monitoring stations for birth cohort studies [15, 22-27]. However, this solution assumes no spatial changes in exposure patterns in time, which may not be applicable in some regions.

The aim of this study was to develop a model capturing the small scale spatial and temporal (monthly and biweekly) variation of nitrogen dioxide $\left(\mathrm{NO}_{2}\right)$. The model integrates land use information, a dispersion model, temporal meteorological data, and measurements from the continuous air quality monitoring background station.

\section{Methods}

\section{Air pollution measurements and study area}

We used two different datasets of $\mathrm{NO}_{2}$ passive sampler measurements conducted continuously between 1998 and 2009. First, 24,499 biweekly $\mathrm{NO}_{2}$ measurements (consecutive 14-day exposure periods), sampled by the
BECO (Berner Wirtschaft) at 101 sites located in a rural environment (i.e., the canton of Bern, area of $5959 \mathrm{~km}^{2}$ and includes several towns with less than 50,000 inhabitants), referred to as the BECO dataset. Second, 4350 consecutive monthly $\mathrm{NO}_{2}$ measurements from 45 sites situated in an urban environment (i.e., the city of Bern with 125,000 inhabitants and an area of $51.6 \mathrm{~km}^{2}$ ) conducted by the AFU (Amt für Umweltschutz Stadt Bern) and referred to as the AFU dataset. Both BECO and AFU are regulatory measurement networks designed to monitor air quality in the canton of Bern. The spatial distribution of the measurement locations is given in Additional file 1: Figure S1.

Site selection by BECO and AFU is aimed at monitoring the different environments generally present in the area: near highways (AFU $22 \%$, BECO $11 \%$ ), residential area near major roads within $100 \mathrm{~m}$ (AFU $36 \%$, BECO $38 \%$ ), rural area near major road within $100 \mathrm{~m}$ (BECO $24 \%$ ), urban setting with medium traffic (AFU $18 \%$ ) and low traffic (AFU $13 \%$ ), near industrial area (BECO $2 \%$ ), sites far from major road in residential (BECO $9 \%$ ) and rural areas (BECO $10 \%$ ), and urban and rural background (AFU $11 \%$, BECO $6 \%$ ). The BECO and the AFU analysed the passive diffusion samplers (Palmes tubes) in their own laboratories. The tubes were protected by a rain and wind shelter and placed at least 1.5 $\mathrm{m}$ above the ground. The precision in these measurements is $\sim 5 \%$ and the measurement of expanded uncertainty is below the recommended $25 \%$ [28].

\section{Potential predictors of $\mathrm{NO}_{2}$}

For each $\mathrm{NO}_{2}$ monitoring location we calculated spatial characteristics of the site (land use, roads, traffic, population, and annual $\mathrm{NO}_{2}$ levels from a dispersion model), meteorological conditions in the area during the time interval of the measurement, and $\mathrm{NO}_{2}$ concentrations from one representative continuous air quality monitoring station (Payerne, rural background site). A comprehensive overview of these predictors including the corresponding data source is provided in Additional file 1: Table S1.

\section{Spatial predictors}

We derived the geographic information system (GIS) variables using ArcGIS10.0, following the procedures in the ESCAPE project protocol [20,29]. We obtained annual $\mathrm{NO}_{2}$ dispersion models (Pollumap, 400x400m resolution) for the whole of Switzerland from METEOTEST for every year between 2000 and 2007. We also obtained a traffic model (Gesamtverkehrsmodell - GMV Bern) for the whole road network of the canton of Bern developed by the Bau-, Verkehrs- und Energiedirektion des Kantons Bern (BVE) which models the annual average traffic of every road during workdays in 2007 . The precision of the model is $5 \%$ for the main road network and 
$8.8 \%$ for the peripheral streets. Land use data for years 2000 and 2006 was issued by the Bundesamt für Umwelt (BAFU) and is based on the European CORINE classification. Population density was provided by the Amt für Geoinformation des Kantons Bern and was based on data collected in the year 2000 . The altitude map as well as the road network (years 2000, 2004 and 2008) were derived from the Swisstopo database.

For land use, roads, traffic, and population density we considered several buffer sizes $(50,100,200,300,500$, and $1000 \mathrm{~m}$ ) reflecting different dispersion patterns and scales of influence (local versus background sources) [30]. Source data for several spatial predictors were available for more than one time-point during the study period (Additional file 1: Table S1). In this situation, we linearly interpolated to estimate the predictors on an annual basis.

\section{Temporal predictors}

Temporal predictors included pollution measured at the representative continuous air quality monitoring (AQM) station reflecting the background level, and several meteorological parameters measured at local meteorological stations. For the background pollutant levels, we used the National Observational Network for Airborne Pollutants (NABEL) AQM station located in the countryside (Payerne). Measurements for temperature, pressure, humidity, wind speed, cloud coverage and solar radiation from local meteorological stations of the Federal Office of Meteorology and Climatology Meteoswiss were downloaded from the IDAweb data Portal (www.meteoswiss.ch). To assign meteorological conditions to all air pollution monitoring sites (AQM, BECO and AFU), we chose the nearest station considering topographical barriers. For the boundary layer height, as a proxy for inversion layer, we used $0.25^{\circ}$ modelled grids from the European Centre for Medium-Range Weather Forecasts (ECMWF) ERA interim dataset. All the temporal predictors had a daily time resolution, which we averaged to correspond to the periods of the $\mathrm{BECO}$ and $\mathrm{AFU} \mathrm{NO}_{2}$ measurements.

\section{Time-space exposure models development}

We developed two distinct models: one for the rural and one for the urban environment. These regression models are based on the following formula:

$$
\log \left(N O_{2}\right)=\sum_{i=1}^{n} \beta_{i} X_{i s}+\sum_{j=1}^{m} \beta_{j} X_{j t}
$$

Where: $\beta$ is a regression coefficient, $X s$ is a spatial covariate, $\mathrm{n}$ is the number of measurement locations, $X t$ is a temporal covariate, and $m$ is the number of observation periods. For model development we applied a log transformation to the dependent variable to take into account the skewed data distribution. No intercept was considered because we included background $\mathrm{NO}_{2}$ levels from the dispersion model. Given that the $\mathrm{R}^{2}$ is not provided in the regression output when the intercept is suppressed (i.e., forced through the origin), we manually calculated the coefficient of determination $\left(R^{2}\right)$. To select the predictors, we first grouped the variables thematically based on prior knowledge: various types of land use, traffic, roads, topography, $\mathrm{NO}_{2}$ from dispersion model, $\mathrm{NO}_{2}$ from continuous $\mathrm{AQM}$, and meteorology (Additional file 1: Table S1). Within some groups, variables were computed for different buffer sizes (e.g., 50, $100,200,300,500$, and $1000 \mathrm{~m}$ ) and several characteristics (e.g., roads represented by distance to street and street density within buffers). We first built a base model including one variable per thematic group chosen a priori according to previous studies. The final variable selection was obtained by using an iterative variable selection procedure combining supervised stepwise forward (bivariate models) and stepwise backward regression to: (a) evaluate the relevance of a thematic group, and (b) select variable(s) per retained thematic group [20, 29]. To determine the most suitable predictor or combination of predictors within a thematic group we tested different options in turn (i.e., buffer size, transformations, splines) and selected the best on the basis of physical/chemical plausibility as well as the $R^{2}$ of the model and $R^{2}$ from ten-fold cross-validation (see section 2.4). For differences in $\mathrm{R}^{2}$ less than $1 \%$, we prioritised small number of variables, similar buffer sizes, the most linear dependency as possible, and no transformation of the variable. This process was reiterated until the model converged. Finally we tested spacetime interactions.

\section{Internal cross-validation}

For the rural and the urban model we performed tenfold cross-validations. This involves using $90 \%$ of the dataset to fit the model, having fixed the variables of the model but allowing the coefficients to change. We then used the derived model to estimate the remaining $10 \%$ of the dataset. We repeated this process ten times in order to estimate all observations once. Finally we compared the estimated with the measured values assessing Pearson $r, R^{2}$ and root mean square errors (RMSE). Validation results were calculated for both the log transformed scale and real concentrations (i.e., exponentiated the predicted values and compared with the measured concentrations).

\section{External validation}

Between years 2010 and 2012 we performed $57 \mathrm{NO}_{2}$ biweekly measurements at the home addresses of a subsample of our BILD (Basel-Bern Infant Lung Development) birth cohort study participants for validation 
purposes (referred to as the "study dataset") [31]. The study was approved by the ethics committee of the Canton of Bern, Switzerland. Informed consent was provided by parents or caregivers. All parents who enrolled in the study from 2010 until end of 2012 were instructed by the study nurses to place a passive Passam sampler outside their home for a 14-day period within the first month after their child's birth. The sites were thus scattered over the Bernese region: one third in the city of Bern and two thirds in the Canton of Bern. For this study dataset, we used samplers provided and analysed by Passam AG, Männedorf, Switzerland. The precision of Passam tubes is comparable to Palmes tubes [28].

For the external validation, depending on the location of the study participants, we used the urban or rural model to estimate the $\mathrm{NO}_{2}$ concentrations during the measurement period. We assessed the same parameters as for the internal cross-validation, in addition to Kappa statistics comparing quartiles of measured and estimated values, and conducted a descriptive analysis to evaluate factors possibly related to the modelling residual (error).

\section{Results}

The $\mathrm{NO}_{2}$ concentration measured at each site in the BECO and AFU datasets is shown in Fig. 1. A similar range in concentrations was measured in both the rural region and the urban area $\left(4\right.$ to $\left.103 \mu \mathrm{g} / \mathrm{m}^{3}\right)$, with a median of $27 \mu \mathrm{g} / \mathrm{m}^{3}$ in the rural region and of $35 \mu \mathrm{g} / \mathrm{m}^{3}$ in the city. The difference between lowest and highest sitespecific $\mathrm{NO}_{2}$ annual mean levels was $61 \mu \mathrm{g} / \mathrm{m}^{3}$ in the rural region, and $45 \mu \mathrm{g} / \mathrm{m}^{3}$ in the urban area. The annual trend in the rural region was $1 \mu \mathrm{g} / \mathrm{m}^{3} /$ year decrease from 1999 to 2001. After 2001 the average annual $\mathrm{NO}_{2}$ concentration was stable at $28 \mu \mathrm{g} / \mathrm{m}^{3}$. The temporal pattern for a sample of the AFU sites indicates temporal variations in the spatial pattern of $\mathrm{NO}_{2}$ over the study area (Additional file 1: Figure S2).

The final rural model included 17 predictors plus 1 interaction term (Table 1) and explained $63 \%$ of the variability in the $\mathrm{NO}_{2}$ measurements $\left(\mathrm{R}^{2}\right)$. The urban model included 13 predictors and 2 interaction terms (Table 2), explaining $54 \%$ of the $\mathrm{NO}_{2}$ variability. Altitude was not considered for the urban model, as there is little variability in elevation within the city. All
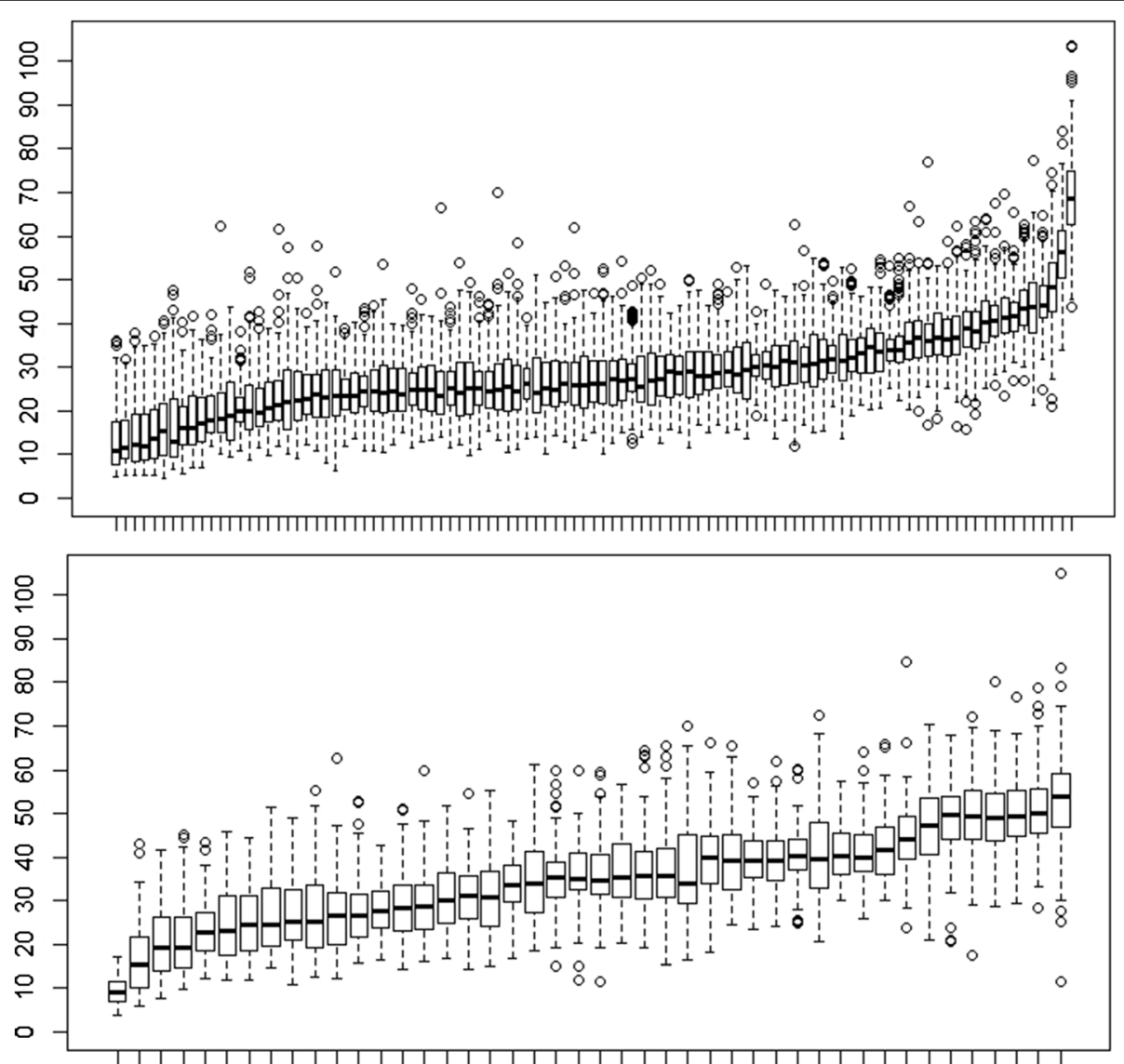

Fig. 1 Descriptive summary of $\mathrm{NO}_{2}$ measurements in the rural region (top) and urban area (bottom) for period 1998 to 2009 for each measuring site in $\mu \mathrm{g} / \mathrm{m}^{3}$ (Box plots for each monitoring location showing median, 1st and 3rd quartile of the measurements for each site, ordered by average $\mathrm{NO}_{2}$ concentration) 
Table 1 Final model for the rural region

\begin{tabular}{|c|c|c|c|c|c|c|c|}
\hline \multirow[t]{2}{*}{ Variables } & \multicolumn{3}{|c|}{ Percentile } & \multirow{2}{*}{$\begin{array}{l}\text { Estimate } \\
\text { per IQR }\end{array}$} & \multirow{2}{*}{$\begin{array}{l}95 \% \mathrm{Cl} \\
\text { lower }\end{array}$} & \multirow{2}{*}{$\begin{array}{l}95 \% \mathrm{Cl} \\
\text { upper }\end{array}$} & \multirow{2}{*}{$\begin{array}{l}\text { Cumulative } \\
\text { Adj. } R^{2}\end{array}$} \\
\hline & 25 & 50 & 75 & & & & \\
\hline Total length of major roads in 100 m buffer * season ${ }^{b}$ & 0 & 294 & 563 & -0.363 & -0.382 & -0.345 & 0.278 \\
\hline Vehicles in $50 \mathrm{~m}$ buffer $\mathrm{N}$ & 67068 & 862600 & 1730503 & 0.146 & 0.141 & 0.150 & 0.334 \\
\hline High density residential land use in $200 \mathrm{~m}$ buffer percent area & 0 & 0 & 0 & 0.410 & 0.389 & 0.430 & 0.372 \\
\hline Log ( $\mathrm{NO}_{2}$ from AQM Payerne) $\log \left(\mathrm{NO}_{2}\right.$ concentration) & 2.28 & 2.62 & 2.98 & 0.250 & 0.239 & 0.262 & 0.406 \\
\hline Log $\left(\mathrm{NO}_{2}\right.$ from dispersion model) $\log \left(\mathrm{NO}_{2}\right.$ concentration) & 2.94 & 3.08 & 3.21 & 0.028 & 0.022 & 0.035 & 0.510 \\
\hline Total length of major roads in $100 \mathrm{~m}$ buffer $\mathrm{m}$ & 0 & 197 & 238 & 0.474 & 0.456 & 0.492 & 0.563 \\
\hline Season (summer $=1$, mid-season $=2$, winter $=3)^{b}$ & 1 & 2 & 3 & 0.181 & 0.158 & 0.203 & 0.578 \\
\hline Sqrt(Traffic in the nearest road) sqrt( $N)$ & 0.0 & 12.5 & 67.3 & 0.098 & 0.092 & 0.104 & 0.591 \\
\hline Industrial land use in $300 \mathrm{~m}$ buffer percent area & 0 & 0 & 0 & 0.321 & 0.300 & 0.342 & 0.603 \\
\hline Population in $100 \mathrm{~m}$ buffer $\mathrm{N}$ & 13.5 & 103.3 & 156.1 & 0.051 & 0.045 & 0.057 & 0.611 \\
\hline Linear time trend year & 2001.7 & 2004.3 & 2007.1 & 0.529 & 0.499 & 0.558 & 0.614 \\
\hline Linear time trend $\wedge 2($ year $\wedge 2)$ & $2001.7^{2}$ & $2004.3^{2}$ & $2007.1^{2}$ & -0.559 & -0.593 & -0.525 & 0.618 \\
\hline Total length of major roads in $1000 \mathrm{~m}$ buffer $\mathrm{m}$ & 0 & 197 & 238 & 0.038 & 0.030 & 0.046 & 0.622 \\
\hline Temperature Celsius & 3.65 & 9.75 & 16.14 & -0.102 & -0.115 & -0.090 & 0.625 \\
\hline Altitude $m$ & 460 & 535 & 561 & -0.032 & -0.036 & -0.028 & 0.628 \\
\hline Low density residential land use in $200 \mathrm{~m}$ buffer percent area & 0.301 & 0.999 & 0.999 & 0.108 & 0.094 & 0.122 & 0.631 \\
\hline Boundary layer height $m$ & 126.2 & 319.7 & 656.2 & -0.022 & -0.030 & -0.014 & 0.632 \\
\hline Total length of major roads in $500 \mathrm{~m}$ buffer $\mathrm{m}$ & 0 & 197 & 238 & 0.012 & 0.004 & 0.020 & 0.632 \\
\hline
\end{tabular}

Model developed without an intercept term. The $\mathrm{R}^{2}$ is not provided in the regression output when the intercept is suppressed; we thus manually calculated the $R^{2}$. The predictors are ordered per decreasing relevance on the basis of incremental $R^{2}$. All $p$-values were $<0.001$

* indicates multiplication of variables

${ }^{a}$ For land use data (high and low density residential land use and industrial land use) we report the estimate per increase from 0 to $100 \%$ of used area instead of per increase of IQR because data distribution is skewed and IQR would be 0

${ }^{b}$ Season categorised as 1: summer (May to August), 2: mid-season (March, April, September, October), 3: winter (November to February)

predictors were statistically significant $(p$-value $<0.001)$ even in the cross-validation process, and were not strongly auto-correlated (Variance Inflation Factors VIF $<10$ [32]) (Additional file 1: Table S2).

In order to compare the relevance of the various predictors in our study areas, model coefficients in Tables 1 and 2 are expressed per interquartile (IQR) change of the predictor variable and ordered per contribution of $R^{2}$ to the whole model. In both models the traffic-related predictors occupied the highest positions in the models, and the most relevant predictor in both models was the interaction between season and a proxy for traffic. Another very relevant (temporal) predictor in both models was the $\mathrm{NO}_{2}$ concentration at the rural background site representing temporal variation of $\mathrm{NO}_{2}$ in the study areas. The explanatory power of the $\mathrm{NO}_{2}$ levels from the dispersion model, representing spatial variability of background concentrations, was somewhat lower in both models than the fixed site $\mathrm{NO}_{2}$ measurements. Both models included population density, and the rural model additionally included a residential land use variable. Residential land use, however, did not improve the performance of the urban model and was not retained in the model. In both models year was treated as polynomial (linear and square term) as the splines showed a non-linear correlation. Both a rural and urban model containing only spatial predictors explained $\sim 40 \%$ of the $\mathrm{NO}_{2}$ variability; temporal predictors alone explained $22 \%$ of the variability in the rural region and $13 \%$ of the variability in the urban area.

For the rural model, the $\mathrm{R}^{2}$ based on the log transformed $\mathrm{NO}_{2}$ measurements was 0.63 and for the untransformed measured concentration was 0.61 (Table 3 ). The same $R^{2} s$ were obtained for the ten-fold internal cross-validation indicating robust coefficient estimates. For the urban model the $\mathrm{R}^{2} \mathrm{~S}$ were somewhat lower but again, identical for the internal cross-validation. The Bland-Altman plots of the internal cross-validation show a negative slope with an over prediction of the lower values (Additional file 1: Figure S3).

The study dataset for external validation recorded 57 $\mathrm{NO}_{2}$ values ranging from 4 to $33 \mu \mathrm{g} / \mathrm{m}^{3}$ (median $15 \mu \mathrm{g} / \mathrm{m}^{3}$ ). Thirty eight measurements were performed in the rural region (median $12.2 \mu \mathrm{g} / \mathrm{m}^{3}$ [IQR 7.9-21]), and 19 measurements were performed in the urban area (median $24.1 \mu \mathrm{g} / \mathrm{m}^{3}$ [IQR $\left.14.8-28.2\right]$ ). The samples were uniformly distributed across the different seasons. We observed that 26 parents placed the samples in the backyard. Based on an analysis of the model residuals for backyard measurements compared to the other outdoor measurements, 
Table 2 Final model for the urban area

\begin{tabular}{|c|c|c|c|c|c|c|c|}
\hline \multirow[t]{2}{*}{ Variables } & \multicolumn{3}{|c|}{ Percentile } & \multirow{2}{*}{$\begin{array}{l}\text { Estimate } \\
\text { per IQR }\end{array}$} & \multirow{2}{*}{$\begin{array}{l}95 \% \mathrm{Cl} \\
\text { lower }\end{array}$} & \multirow{2}{*}{$\begin{array}{l}95 \% \mathrm{Cl} \\
\text { upper }\end{array}$} & \multirow{2}{*}{$\begin{array}{l}\text { Cumulative } \\
\text { Adj. } R^{2}\end{array}$} \\
\hline & 25 & 50 & 75 & & & & \\
\hline Sqrt (vehicles in $100 \mathrm{~m}^{\circ}$ buffer) ${ }^{*}$ season $^{\mathrm{b}}$ & 1728 & 3696 & 6117 & -0.219 & -0.265 & -0.172 & 0.291 \\
\hline $\log \left(\mathrm{NO}_{2}\right.$ from dispersion model) $\log \left(\mathrm{NO}_{2}\right.$ concentration) & 3.21 & 3.28 & 3.37 & 0.052 & 0.039 & 0.065 & 0.341 \\
\hline Log ( $\mathrm{NO}_{2}$ from AQM Payerne) $\log \left(\mathrm{NO}_{2}\right.$ concentration) & 2.3 & 2.68 & 3.03 & 0.216 & 0.181 & 0.252 & 0.372 \\
\hline Sqrt (vehicles in 100 m buffer) & 1391 & 1997 & 3074 & 0.404 & 0.362 & 0.446 & 0.437 \\
\hline $\log (1 /$ distance to the nearest major road) $\log (1 / \mathrm{m})$ & -4.08 & -2.95 & -2.61 & 0.163 & 0.144 & 0.181 & 0.470 \\
\hline Linear time trend year & 2002.6 & 2005.2 & 2007.7 & 0.477 & 0.387 & 0.567 & 0.488 \\
\hline Season (summer $=1$, mid-season $=2$, winter $=3)^{b}$ & 1 & 2 & 3 & 0.191 & 0.118 & 0.264 & 0.499 \\
\hline Industrial land use in $300 \mathrm{~m}$ buffer percent area & 0 & 0 & 0.237 & 0.436 & 0.384 & 0.487 & 0.506 \\
\hline Population in $100 \mathrm{~m}$ buffer $\mathrm{N}$ & 0.95 & 141 & 323 & 0.118 & 0.097 & 0.139 & 0.514 \\
\hline (Total length of major roads in $100 \mathrm{~m}$ buffer) ${ }^{\wedge} 2(m \wedge 2)$ & 26931 & 48969 & 147510 & 0.296 & 0.259 & 0.334 & 0.519 \\
\hline Total length of major roads in $100 \mathrm{~m}$ buffer $\mathrm{m}$ & 164 & 221 & 384 & -0.414 & -0.472 & -0.356 & 0.534 \\
\hline Linear time trend $\wedge 2($ year $\wedge 2)$ & $2002.6^{2}$ & $2005.2^{2}$ & $2007.7^{2}$ & -0.462 & -0.563 & -0.36 & 0.540 \\
\hline Temperature Celsius & 3.4 & 9.05 & 15.59 & -0.081 & -0.126 & -0.035 & 0.540 \\
\hline (Boundary layer height)^2 (m^2) & 16723 & 79082 & 359729 & -0.013 & -0.024 & -0.002 & 0.541 \\
\hline Total length of major roads in $100 \mathrm{~m}$ buffer * temperature & 0 & 1485 & 3807 & 0.034 & 0 & 0.069 & 0.541 \\
\hline
\end{tabular}

Model developed without an intercept term. The $\mathrm{R}^{2}$ is not provided in the regression output when the intercept is suppressed; we thus manually calculated the R2. The predictors are ordered per decreasing relevance on the basis of incremental $\mathrm{R}^{2}$. Most $p$-values were $<0.001 ; p$-value for "Total length of major roads in $100 \mathrm{~m}$ buffer * temperature" was $<0.05$

* indicates multiplication of variables

${ }^{a}$ For land use data (high and low density residential land use and industrial land use) we report the estimate per increase from 0 to $100 \%$ of used area instead of per increase of IQR because data distribution is skewed and IQR would be 0

${ }^{\mathrm{b}}$ Season categorised as 1: summer (May to August), 2: mid-season (March, April, September, October), 3: winter (November to February)

backyard measurements were corrected by a factor of 1.104 in urban settings and 1.275 in rural settings.

After backyard correction, the external validation of the urban model had comparable Pearson $r, R^{2}$, and RMSE to the model itself and the internal crossvalidation (Table 3 ). The urban model performed better in the external validation, with higher $R^{2}$ and a remarkably lower RMSE. The Bland-Altman plot of the study dataset, comparing measured and predicted values for the rural or urban model depending on the location of measurement, showed no evident slope but still an overestimation of $2.1 \mu \mathrm{g} / \mathrm{m}^{3}$ (Additional file 1: Figure S4).
For the external validation, an exposure assessment based on quartile resulted in a weighted Kappa coefficient of 0.671 between predicted and measured $\mathrm{NO}_{2}$ levels (Additional file 1: Table S3).

\section{Discussion}

The rural and urban models that we developed are based on biweekly and monthly measurements and have been externally validated. We found that the most important predictors, as indicated by the IQR change of the predictor variable, in both models were those related to traffic. A finding that may be of particular interest for policy makers is that the models show the overwhelming impact of the

Table 3 Performance and validation of the final models

\begin{tabular}{|c|c|c|c|c|c|c|}
\hline \multirow[t]{2}{*}{ Area } & \multirow[t]{2}{*}{ Evaluation } & \multicolumn{2}{|l|}{ Pearson $r$} & \multicolumn{2}{|l|}{$R^{2}$} & \multirow{2}{*}{$\begin{array}{l}\text { RMSE } \\
\mu \mathrm{g} / \mathrm{m}^{3}\end{array}$} \\
\hline & & $\log \left(\mu \mathrm{g} / \mathrm{m}^{3}\right)$ & $\mu \mathrm{g} / \mathrm{m}^{3}$ & $\log \left(\mu \mathrm{g} / \mathrm{m}^{3}\right)$ & $\mu \mathrm{g} / \mathrm{m}^{3}$ & \\
\hline \multirow[t]{3}{*}{ Rural } & Model & 0.79 & 0.78 & 0.63 & 0.61 & 5.86 \\
\hline & Internal cross-validation & 0.80 & 0.78 & 0.63 & 0.61 & 5.86 \\
\hline & External validation & 0.77 & 0.82 & 0.58 & 0.68 & 3.21 \\
\hline \multirow[t]{3}{*}{ Urban } & Model & 0.74 & 0.67 & 0.54 & 0.45 & 6.96 \\
\hline & Internal cross-validation & 0.74 & 0.67 & 0.54 & 0.45 & 6.96 \\
\hline & External validation & 0.82 & 0.83 & 0.67 & 0.69 & 3.35 \\
\hline
\end{tabular}

Internal cross-validation was based on ten-fold cross-validation, and external validation used the study dataset. We compared measured and predicted values on the log scale, on which the models were developed, and as concentrations by exponentiating the predictions. The root mean square errors (RMSE) are derived from the comparison of $\mathrm{NO}_{2}$ concentrations only 
traffic-related predictors on air pollution over the temporal component, and the data did not show any downward trend over the last years.

We showed the importance of having both a temporal and spatial component in such an air pollution exposure model. Estimation based on temporal components alone would only explain 12 to $22 \%$ of the $\mathrm{NO}_{2}$ variability, and the spatial component alone only $40 \%$. Combined, however, for log transformed models we reached an $\mathrm{R}^{2}$ of 0.63 in the rural setting and 0.54 in urban areas. It seems that the duration of the $\mathrm{NO}_{2}$ measurement plays a role for the temporal $\mathrm{R}^{2}$. For the rural model with biweekly measurements a larger proportion of the variance is explained by temporal predictors compared to the urban model, which is based on monthly measurements. In general, however, the $\mathrm{R}^{2} \mathrm{~s}$ of both models are comparable to annual LUR models for a wide range of European cities (ESCAPE study, 36 study areas, $\left.R^{2}: 0.31-0.87\right)$ [20]. The comparison is even better when we average our data to generate annual LUR models. Model performance, as indicated by $R^{2}$, for annual models using only the spatial predictors in our final model ranged from 64 to $75 \%$ for rural and 48 to $74 \%$ for the urban area (data not shown).

Our approach has several clear strengths compared to previous models. The first is the number of available temporal observations. Previously published models were often limited to annual averages based typically on three measurement periods per year (one per season) [21, 33, 34], whereas our model was developed using 12 to 26 measurements per year over a period of more than ten years. This wealth of data enabled us to develop a more robust model which can be used predictively to assign exposures to cohort studies. A similar network of passive samplers was recently used to develop 14-day $\mathrm{NO}_{2}$ concentration maps for the city of Zurich, Switzerland [35]. That study, however, aimed more generally at air quality assessment for cities rather than prediction for individuals during critical time windows.

Given the number of predictor variables in the model, one concern is that model might be over-specified. However, we can rule this out because of similar results for the internal cross-validation and external validation. Nevertheless, 10 variables in the rural model and 5 in the urban model added only $3 \%$ to the explained variance. To evaluate the impact of this on the estimates we tested a model without these variables and found that $\mathrm{R}^{2}$ in the external validation decreased from 0.63 to 0.60 (rural model) and from 0.54 to 0.49 (urban model). We further found that the degree of overestimation increased from $2.11 \mu \mathrm{g} / \mathrm{m}^{3}$ to $3.29 \mu \mathrm{g} / \mathrm{m}^{3}$. Since the dataset is very large, and the extra work to include these variables is negligible, we opted to aim at the best model which explains most of the variance. Using a large number of temporal measurements also minimised the likelihood of over-fitting the model [36]. An internal cross-validation that does not agree with the original model would be an indication for this kind of problem. In our study the ten-fold internal cross-validation showed the same values of performance $\left(R^{2}\right.$, Pearson $r$ and RMSE) as the original model, attesting to the stability of the model. In our estimation process we did not account for temporal and spatial correlation of the measurements. This affects the confidence intervals of the model coefficients but is unlikely to produce a bias. Exposure prediction is based on the central estimates only.

We were able to validate the model using an external dataset with measurements performed in the same area but at different sites and in a different time frame (1998-2009 for the model training measurements vs. 2010-2012 for the external validation). The advantage of the study dataset is that the sites reflect the residence (home location) of study participants, thus actual exposure locations. In contrast, the AFU and BECO measurement sites are not expected to fully reflect the spatial distribution and variation in exposures at the home addresses of our BILD birth cohort participants because the networks were designed to over-represent near street environments. We found that the predictions of the external dataset were overestimated. A part of this overestimation could be attributed to the fact that study dataset measurements were partly done in the backyard of the residence. After applying a backyard correction, an overestimation of $\sim 2.1 \mu \mathrm{g} / \mathrm{m}^{3}$ was still seen. Possible reasons for this are the known overestimation of lower values of such kind of regression models. Since the study participants generally do not live in air pollution hot spots, such as near highways, the dataset is situated in the lower range where we observe this systematic error as a consequence of regression to the mean. Another explanation could be the differences in sampling methodology (Passam vs Palmes tubes), however this is unlikely as the literature to date reports good agreement between the two equipment types [28]. A further consideration could be the $\mathrm{NO}_{2}$ trend over time. The training dataset encompassed the years 1998 to 2009 and the study dataset covered 2010 until 2012. A decrease in $\mathrm{NO}_{2}$ levels in recent years $[37,38]$ could explain an overestimation of values by the model. However, a decrease in overall $\mathrm{NO}_{2}$ levels has not been observed since 2001 in our dataset. Therefore this hypothesis is unlikely. Most importantly, however, we found that the prediction of the study dataset using our models was reasonable. The external validation $R^{2}$ based on the rural measurements was the same as the model $R^{2}$, while for urban measurements the external validation $R^{2}$ was higher, probably due to the restricted range.

Some birth cohorts in Europe are using temporally adjusted land use regression models based on one or a few 
AQM stations [22, 26, 39]. They apply a global adjustment, thus the spatial pattern remains the same across cohort period which is not realistic. Given that we have a complex topography and temporal variation of the spatial pattern (Additional file 1: Figure S2) in our study area, a global adjustment would not suffice. In comparison to these earlier studies, our approach more realistically and systematically models the spatial and temporal variability of air pollution exposures. Our results also suggest that the spatial component alone is unlikely to reflect well the variations in air pollution at shorter time periods, such as those needed for birth cohorts.

\section{Conclusions}

Our model could predict quite well biweekly or monthly $\mathrm{NO}_{2}$ levels at independent measurement locations. As such, it will be used to predict $\mathrm{NO}_{2}$ exposure during pregnancy for various time intervals during and shortly after pregnancy to support the investigation of subsequent health effects. To this end, we can estimate exposure for individual cohort participants by specific time windows (e.g., trimesters, full pregnancy, or $1^{\text {st }}$ year of life). Thus, our approach is an exemplary tool for air pollution exposure prediction in time-sensitive epidemiologic research with seasonally-vulnerable health effects such as the effects occurring during pregnancy.

\section{Additional file}

Additional file 1: Figure S1. Spatial distribution of the BECO (rural) and AFU (urban) measurement locations in the canton of Bern, displayed on background $\mathrm{NO}_{2}$ from the 2007 dispersion model. Figure S2. NO2 levels measured in a sample of urban monitoring sites during the year 2007. Figure S3. Internal validation Bland-Altman plot of predicted and measured values in the rural region (top) and urban area (bottom) in the log scale. Figure S4. Bland-Altman plot for external validation in $\mu \mathrm{g} / \mathrm{m}^{3}$ (rural or urban model without intercept, corrected for backyard measurements). Table S1. Potential predictors of $\mathrm{NO}_{2}$. Table S2. Variance Inflation Factors (VIF) of main predictors in the rural and urban model. Table S3. Kappa statistics for External validation - measured vs estimated concentration in quartiles. (DOCX $1047 \mathrm{~kb})$

\section{Acknowledgements}

This work was supported by the Swiss National Science Foundation, grant number 324730_144280. We thank the parents in BILD who contributed to the study dataset by placing a passive sampler outside their homes; AFU (Amt für Umweltschutz Stadt Bern), BAFU (Bundesamt für Umwelt Kanton Bern), Amt für Geoinformation and BVE (Bau-Verkehrs-Energiedirektion) Kanton Bern, NABEL (Nationales Beobachtungsnetz für Luftfremdstoffe), Meteotest, Meteoswiss and Swisstopo for providing data and maps (also used in the TOC art). We further thank Janet Maccora for her support on an early draft of the manuscript and figures.
\end{abstract}

\section{Authors' contributions}

$E P, E D, G S, D V, M T, P L, U F$ and MR designed and conducted the research; UF is the principle investigator of BILD (Basel-Bern Infant Lung Development) birth cohort; EP and ED analysed the data; EP and DV wrote the paper; MR had primary responsibility for the final content. All authors read and approved the final manuscript.

\section{Competing interests}

The authors declare that they have no competing interests.

\section{Author details}

${ }^{1}$ University Children's Hospital (UKBB), University of Basel, Spitalstrasse $33 \mathrm{CH}$ 4056, Basel, Switzerland. ${ }^{2}$ Swiss Tropical and Public Health Institute (Swiss TPH), Socinstrasse 57, 4051, Basel, Switzerland. ' University of Basel, Basel, Switzerland. ${ }^{4}$ Division of Paediatric Pulmonology, Department of Paediatrics, Inselspital and University of Bern, Bern, Switzerland.

Received: 23 July 2015 Accepted: 16 May 2016

Published online: 25 May 2016

\section{References}

1. Rehan VK, Liu J, Sakurai R, Torday JS. Perinatal nicotine-induced transgenerational asthma. Am J Physiol Lung Cell Mol Physiol. 2013;305(7): L501-7. doi:10.1152/ajplung.00078.2013.

2. Li YF, Langholz B, Salam MT, Gilliland FD. Maternal and grandmaternal smoking patterns are associated with early childhood asthma. Chest. 2005: 127(4):1232-41. doi:10.1378/chest.127.4.1232

3. Wick P, Malek A, Manser P, Meili D, Maeder-Althaus X, Diener L, et al. Barrier capacity of human placenta for nanosized materials. Environ Health Perspect. 2010;118(3):432-6. doi:10.1289/ehp.0901200.

4. Proietti E, Roosli M, Frey U, Latzin P. Air pollution during pregnancy and neonatal outcome: a review. J Aerosol Med Pulm Drug Deliv. 2013;26(1):9-23. doi:10.1089/jamp.2011.0932.

5. Stern G, Latzin P, Roosli M, Fuchs O, Proietti E, Kuehni C, et al. A prospective study of the impact of air pollution on respiratory symptoms and infections in infants. Am J Respir Crit Care Med. 2013;187(12):1341-8. doi:10.1164/rccm. 201211-20080C.

6. Latzin P, Roosli M, Huss A, Kuehni CE, Frey U. Air pollution during pregnancy and lung function in newborns: a birth cohort study. Eur Respir J. 2009;33(3):594-603. doi:10.1183/09031936.00084008.

7. Latzin P, Frey U, Armann J, Kieninger E, Fuchs O, Roosli M, et al. Exposure to moderate air pollution during late pregnancy and cord blood cytokine secretion in healthy neonates. PLoS One. 2011;6(8):e23130. doi:10.1371/ journal.pone.0023130.

8. Son JY, Bell ML, Lee JT. Survival analysis of long-term exposure to different sizes of airborne particulate matter and risk of infant mortality using a birth cohort in Seoul, Korea. Environ Health Perspect. 2011;119(5):725-30. doi:10. 1289/ehp.1002364.

9. Herr CE, Dostal M, Ghosh R, Ashwood P, Lipsett M, Pinkerton KE, et al. Air pollution exposure during critical time periods in gestation and alterations in cord blood lymphocyte distribution: a cohort of livebirths. Environ Health. 2010;9:46. doi:10.1186/1476-069X-9-46.

10. Baiz N, Slama R, Bene MC, Charles MA, Kolopp-Sarda MN, Magnan A, et al. Maternal exposure to air pollution before and during pregnancy related to changes in newborn's cord blood lymphocyte subpopulations. The EDEN study cohort. BMC Pregnancy Childbirth. 2011;11:87. doi:10.1186/1471-239311-87.

11. Darrow LA, Klein M, Strickland MJ, Mulholland JA, Tolbert PE. Ambient air pollution and birth weight in full-term infants in Atlanta, 1994-2004. Environ Health Perspect. 2011;119(5):731-7. doi:10.1289/ehp.1002785.

12. Gehring $U$, van Eijsden $M$, Dijkema $M B$, van der Wal MF, Fischer $P$, Brunekreef B. Traffic-related air pollution and pregnancy outcomes in the Dutch ABCD birth cohort study. Occup Environ Med. 2011;68(1):36-43. doi: 10.1136/oem.2009.053132.

13. Madsen C, Gehring U, Walker SE, Brunekreef B, Stigum H, Naess O, et al. Ambient air pollution exposure, residential mobility and term birth weight in Oslo, Norway. Environ Res. 2010;110(4):363-71. doi:10.1016/j.envres.2010.02.005.

14. Dadvand P, Parker J, Bell ML, Bonzini M, Brauer M, Darrow LA, et al. Maternal exposure to particulate air pollution and term birth weight: a multi-country evaluation of effect and heterogeneity. Environ Health Perspect. 2013;121(3): 267-373. doi:10.1289/ehp.1205575.

15. Pedersen M, Giorgis-Allemand L, Bernard C, Aguilera I, Andersen AM, Ballester $F$, et al. Ambient air pollution and low birthweight: a European cohort study (ESCAPE). Lancet Respir Med. 2013;1(9):695-704. doi:10.1016/ S2213-2600(13)70192-9.

16. Armstrong BG. Effect of measurement error on epidemiological studies of environmental and occupational exposures. Occup Environ Med. 1998; 55(10):651-6. 
17. Van den Hooven EH, Pierik FH, Van Ratingen SW, Zandveld PY, Meijer EW, Hofman A, et al. Air pollution exposure estimation using dispersion modelling and continuous monitoring data in a prospective birth cohort study in The Netherlands. Environ Health. 2012;11:9. doi:10.1186/1476-069X$11-9$.

18. Malmqvist E, Rignell-Hydbom A, Tinnerberg H, Bjork J, Stroh E, Jakobsson K, et al. Maternal exposure to air pollution and birth outcomes. Environ Health Perspect. 2011;119(4):553-8. doi:10.1289/ehp.1002564.

19. Briggs DJ. The role of GIS: Coping with space (and time) in air pollution exposure assessment. J Toxicol Environ Health Part A. 2005;68:1243-61.

20. Beelen R, Hoek G, Vienneau D, Eeftens M, Dimakopoulou K, Pedeli X, et al. Development of NO2 and NOx land use regression models for estimating air pollution exposure in 36 study areas in Europe - The ESCAPE project. Atmos Environ. 2013;72:10-23. http://dx.doi.org/10.1016/j.atmosenv.2013.02.037.

21. Hoek G, Beelen R, de Hoogh K, Vienneau D, Gulliver J, Fischer P, et al. A review of land-use regression models to assess spatial variation of outdoor air pollution. Atmos Environ. 2008;42(33):7561-78.

22. Slama R, Morgenstern V, Cyrys J, Zutavern A, Herbarth O, Wichmann HE, et al. Traffic-related atmospheric pollutants levels during pregnancy and offspring's term birth weight: a study relying on a land-use regression exposure model. Environ Health Perspect. 2007;115(9):1283-92. doi:10.1289/ ehp.10047.

23. Ross Z, Ito K, Johnson S, Yee M, Pezeshki G, Clougherty JE, et al. Spatial and temporal estimation of air pollutants in New York City: exposure assignment for use in a birth outcomes study. Environ Health. 2013;12:51. doi:10.1186/ 1476-069X-12-51.

24. Laurent O, Wu J, Li L, Chung J, Bartell S. Investigating the association between birth weight and complementary air pollution metrics: a cohort study. Environ Health. 2013;12:18. doi:10.1186/1476-069x-12-18.

25. Wilhelm M, Ghosh JK, Su J, Cockburn M, Jerrett M, Ritz B. Traffic-related air toxics and term low birth weight in Los Angeles County, California. Environ Health Perspect. 2012;120(1):132-8. doi:10.1289/ehp.1103408.

26. Iniguez C, Ballester F, Estarlich M, Esplugues A, Murcia M, Llop S, et al. Prenatal exposure to traffic-related air pollution and fetal growth in a cohort of pregnant women. Occup Environ Med. 2012;69(10):736-44. doi:10.1136/ oemed-2011-100550.

27. Ghosh JK, Wilhelm M, Su J, Goldberg D, Cockburn M, Jerrett M, et al. Assessing the influence of traffic-related air pollution on risk of term low birth weight on the basis of land-use-based regression models and measures of air toxics. Am J Epidemiol. 2012;175(12):1262-74. doi:10.1093/ aje/kwr469.

28. Hafkenscheid T, Fromage-Marriette A, Goelen E, Hangartner M, Pfeffer U, Plaisance $\mathrm{H}$, et al. Review of the Application of Diffusive Samplers for the Measurement of Nitrogen Dioxide in Ambient Air in the European Union. Institute for Environment and Sustainability, Luxembourg: Office for Official Publications of the European Communities ; 2009.

29. Eeftens M, Beelen R, de Hoogh K, Bellander T, Cesaroni G, Cirach M, et al. Development of land use regression models for PM2.5, PM2.5 Absorbance, PM10 and PMcoarse in 20 European study areas; results of the ESCAPE project. Environ Sci Technol. 2012;46(20):11195-205. doi:10.1021/es301948k.

30. Su JG, Jerrett M, Beckerman B. A distance-decay variable selection strategy for land use regression modeling of ambient air pollution exposures. Sci Total Environ. 2009;407(12):3890-8. doi:10.1016/j.scitotenv.2009.01.061.

31. Fuchs $O$, Latzin $P$, Kuehni CE, Frey U. Cohort profile: the Bern infant lung development cohort. Int J Epidemiol. 2012;41(2):366-76.

32. Kutner MH, Nachtsheim CJ, Neter J. Applied Linear Regression Models. 4th ed. Irwin: McGraw-Hill; 2004.

33. Briggs DJ, Collins S, Elliott P, Fischer P, Kingham S, Lebret E, et al. Mapping urban air pollution using GIS: a regression-based approach. Int J GIS. 1997; 11(7):699-718.

34. Wang M, Beelen R, Eeftens M, Meliefste K, Hoek G, Brunekreef B. Systematic evaluation of land use regression models for NO2. Environ Sci Technol. 2012:46(8):4481-9. doi:10.1021/es204183v.

35. Mueller MD, Wagner M, Barmpadimos I, Hueglin C. Two-week NO2 maps for the City of Zurich, Switzerland, derived by statistical modelling utilizing data from a routine passive diffusion sampler network. Atmos Environ. 2015; 106(0):1-10. http://dx.doi.org/10.1016/j.atmosenv.2015.01.049.

36. Wang M, Beelen R, Basagana X, Becker T, Cesaroni G, de Hoogh K, et al. Evaluation of land use regression models for $\mathrm{NO} 2$ and particulate matter in 20 European study areas: the ESCAPE project. Environ Sci Technol. 2013; 47(9):4357-64. doi:10.1021/es305129t.
37. EEA. Air pollution fact sheet 2013, Switzerland. Copenhagen: European Environment Agency; 2013.

38. Liu LJS, Tsai M-Y, Keidel D, Gemperli A, Ineichen A, Hazenkamp-von Arx M, et al. Long-term exposure models for traffic related NO2 across geographically diverse areas over separate years. Atmos Environ. 2012;46: 460-71. http://dx.doi.org/10.1016/j.atmosenv.2011.09.021.

39. Larsen PS, Kamper-Jorgensen M, Adamson A, Barros H, Bonde JP, Brescianini $S$, et al. Pregnancy and birth cohort resources in Europe: a large opportunity for aetiological child health research. Paediatr Perinat Epidemiol. 2013;27(4): 393-414. doi:10.1111/ppe.12060.

\section{Submit your next manuscript to BioMed Central and we will help you at every step:}

- We accept pre-submission inquiries

- Our selector tool helps you to find the most relevant journal

- We provide round the clock customer support

- Convenient online submission

- Thorough peer review

- Inclusion in PubMed and all major indexing services

- Maximum visibility for your research

Submit your manuscript at www.biomedcentral.com/submit 